\title{
Application of electrokinetic soil flushing to four herbicides: a comparison
}

\author{
E. Vieira dos Santos ${ }^{1}$, F. Souza ${ }^{2}$, C. Saez ${ }^{3}$, P. Cañizares ${ }^{3}$, M.R.V. Lanza ${ }^{2}$, C.A. \\ Martinez-Huitle ${ }^{1}$, M.A. Rodrigo ${ }^{3, *}$ \\ ${ }^{1}$ Institute of Chemistry, Federal University of Rio Grande do Norte, Lagoa Nova CEP \\ 59078-970, Natal, RN, Brazil \\ ${ }^{2}$ Instituto de Química de São Carlos, Universidade de São Paulo, P.O. Box 780, CEP- \\ 13560-970, São Carlos, SP, Brazil. \\ ${ }^{3}$ Department of Chemical Engineering. Universidad de Castilla La Mancha. Facultad de \\ Ciencias y Tecnologías Químicas. Enrique Costa Building. Campus Universitario s/n. \\ 13071 Ciudad Real. Spain
}

\section{Abstract}

In this work, four bench-scale plants containing soil spiked with four herbicides $(2,4-$ Dichlorophenoxyacetic acid (2,4-D), oxyfluorfen, chlorsulfuron and atrazine) undergo treatment consisting of an electrokinetic soil flushing (EKSF). Results clearly demonstrate that efficiency of EKSF depends on the chemical characteristic of the pesticide used. The amount of pesticide collected in the anode well is more significant than that collected in the cathode wells, indicating that the electromigration is much more important than drainage by electro-osmotic flux for this application. After $15 \mathrm{~d}$ of treatment, the 2,4-D is the pesticide most efficiently removed (95\% of removal), while chlorsulfuron is the pesticide more resilient to the treatment. Additionally, volatilization was found to be a process of the major significance in the application of electrokinetic techniques to soil polluted with herbicides and because of that it should always be taken into account in the future design of full-scale processes.

\section{Keywords}

Herbicides, Electromigration, Soil, Electrokinetic soil flushing 


\section{Highlights}

$4 \quad-\quad$ EKSF can remediate soils polluted with ionic and non-ionic herbicides

$5 \quad-\quad$ Herbicides can be mobilized towards the electrodes by electromigration

$6 \quad-\quad$ Herbicides can be transported towards the cathode by electroosmotic dragging.

$7 \quad$ - Volatilization has a great importance and should be accounted in large processes

$8-$ After $15 \mathrm{~d}$ long treatment, more than $80 \%$ of pesticide is removed.

9

$11 *$ *mail to whom all correspondence should be addressed: manuel.rodrigo@uclm.es 
2 Soil pollution is an important problem in modern society. The diffuse pollution and

3 particularly the effects of this pollution on water reservoirs is becoming an issue of the

4 major significance. Consequently, soil remediation is becoming a very promising area of

5 study within environmental engineering and the development of novel and efficient

6 treatment technologies (such as the electrochemically assisted technologies) is becoming

7 more and more important (Hamdan et al., 2014).

8 Among these technologies, the electrokinetic soil flushing (EKSF) is gaining attention in

9 the recent years. When polluted soil undergoes the effect of an electric field between anodes and cathodes, electroosmosis, electromigration and electrophoresis mobilize the pollutants contained in the soil. Under suitable conditions, these processes can be used to remediate the soil, transferring the pollution to a flushing fluid that can be then treated. EKSF process has been studied for the remediation of soils polluted with different contaminants (Trellu et al., 2016) such as pesticides (Ribeiro et al., 2011; Gomes et al., 2012; Guedes et al., 2014; Ribeiro et al., 2005), hydrocarbons (Gomez et al., 2009; Alcantara et al., 2010, 2012; Mendez et al., 2012; Lopez-Vizcaino et al., 2014a, b; Mousset et al., 2014; Bocos et al., 2015) and heavy metals (Maturi and Reddy, 2006, 2008). In fact, the removal of pesticides using EKSR has become a hot topic (Jackman et al., 2001; Ribeiro et al., 2005; Harbottle et al., 2009; Ribeiro et al., 2011; Gomes et al., 2012; Rodrigo et al., 2014), and even recent works were focussed not only on the efficiency of EKSF but also on the integration of this technique with other remediation technologies such as bioremediation and permeable reactive barriers (Trellu et al., 2016). In general, removal efficiencies reported with spiked kaolinite (as model of low permeable soil) show the influence of electrode arrangements, flushing fluid and electric field. However, the loss of the pollutants by filtration, dragging of superficial water or 
1 evaporation have not been clearly stated and these are important points to be capable to

2 control the diffusion of pesticides into the soil (Jackman et al., 2001; Ribeiro et al., 2005;

3 Harbottle et al., 2009; Ribeiro et al., 2011).

4 Regarding the pesticides, it is important to point out the high risk associated with the

5 hazardousness of these pollutants and their wide range of chemical properties. Therefore,

6 it makes necessary to limit their presence in the environment and to develop efficient

7 technologies of soil and water remediation (Dombek et al., 2004; Castelo-Grande et al.,

8 2005; Malpass et al., 2006; Cao et al., 2015). Among the chemical properties, water

9 solubility and volatilization of pesticides influence significantly the efficiency of the

10 remediation processes and thus determine the feasibility of the treatment.

11 Taking into account this background, this work aims to compare in the same experimental conditions the remediation of four pesticides (2,4-Dichlorophenoxyacetic acid (2,4-D), Chorosulfuron, Atrazine and Oxyfluorfen) by EKSF. These herbicides have different characteristics, in terms of solubility and volatility, and they were selected in order to understand the mechanisms accomplished in the soil when this type of technologies are applied. To do this, $15 \mathrm{~d}$ long tests in bench scale soil columns are used. The scale is large enough to account the important processes happening in the soil in more realistic conditions. Synthetic soil has been used in order to prevent the interaction of the processes studied with other processes that can mask their influence.

Materials and methods

Chemicals. Kaolinite, provided by Manuel Riesgo Chemical Products (Madrid, Spain), was used as a model of clay soil. Properties of this synthetic clay soil were provided by the commercial supplier, and are detailed in the Table SM-1 of the Supplementary Material (SM). All chemicals, including anhydrous sodium sulfate, sodium phosphate 
1 (Fluka, Spain), 2,4-D, Chorosulfuron, Atrazine and Oxyfluorfen (Sigma-Aldrich) were

2 analytical grade and used as received. Acetonitrile HPLC grade (Sigma-Aldrich, Spain)

3 was used for the mobile phase. Double deionized water (Millipore Milli-Q system,

4 resistivity $=18.2 \mathrm{M} \Omega \mathrm{cm}$ at $25^{\circ} \mathrm{C}$ ) was used to prepare all solutions. Sodium Dodecyl

5 Sulfate (Fluka, Spain) used as solubilizing agent while hexane and ethyl acetate (Sigma-

$6 \quad$ Aldrich, Spain) were used as solvent for extraction of liquid and solid samples.

7 Electrokinetic cell. Bench setup used in this work is shown in the SM (Fig. SM-1). It

8 was made of transparent methacrylate and divided into five compartments. The central

9 compartment with length of $20 \mathrm{~cm}$ was loaded with herbicide-polluted soil, which was compacted manually and separated of the electrode compartments by a $0.5 \mathrm{~mm}$ nylon mesh. One of these compartments served as anode and the other as cathode. Graphite electrodes $(10.0 \mathrm{~cm} \times 10.0 \mathrm{~cm} \times 1.0 \mathrm{~cm})$ provided by Carbosystem (Madrid, Spain) were used as electrodic material. Each electrode compartment was connected to an additional compartments to collect the liquid overflowing from the wells that is transported by the electrokinetic processes. The experiments were performed in a potentiostatic mode, i.e., setting a voltage at $1 \mathrm{~V} \mathrm{~cm}^{-1}$. The duration of the experiment was two weeks.

Preparation of the soil. The model soil was spiked with $960 \mathrm{~mL}$ of herbicide aqueous solutions (100 $\mathrm{mg} \mathrm{L}^{-1}$ ) until attaining an initial pollutant concentration of $30 \mathrm{mg}$ per kg of soil. In the case of atrazine and oxyfluorfen solutions, sodium dodecyl sulfate was used as solubilizing agent (1000 $\left.\mathrm{mg} \mathrm{L}^{-1}\right)$. The initial target moisture level of the soil was $30 \%$. Polluted soil was compacted manually in the central compartment of the cell (3 kg). This compaction was carefully done to avoid the formation of heterogeneities zones in the soil, which can result in preferential paths for the fluid transport. In all cases, tap water was used as flushing fluid. The level of the anode wells were maintained by means of a level 
1 regulation loop. On contrary, from cathode well water was daily pumped. Evaporation

2 was estimated by mass balance.

3

4 Experimental procedure. During the experiments, the electrical current, the temperature

5 on different portions of the soil, the electroosmotic volume removed from the cathodic

6 collector, $\mathrm{pH}$, conductivity, pesticide and TOC concentration of the electroosmotic fluid

7 were monitored. At the end of the experiment, a post mortem analysis was carried out to

8 evaluate the final state of the treated soil (post-study characterization): $\mathrm{pH}$, conductivity,

9 humidity, herbicide and TOC concentrations were measured. For this analysis, the soil compartment was divided into sixteen portions (Fig. SM-1b of SM). Sampling procedure of each soil-portion consists of taking it out carefully from the set up and manually homogenizing it. After that, representative samples were taken for carrying out each analysis. Profiles of concentrations were obtained by sampling solutions at predetermined time intervals during the electrolysis process (robustness of the results was evaluated by four independent analyses).

Analysis procedures. Measurement of the moisture was carried out by drying the soil samples in an oven for $24 \mathrm{~h}$ at $105^{\circ} \mathrm{C}$. Moisture was estimated taking into account the weight difference in the samples before and after drying. For the determination of the $\mathrm{pH}$ and conductivity in the soil samples, the standard method (E.P.A.-9045C, 1995) of the saturated paste was used. This method consists of the mixture of $10 \mathrm{~g}$ of dry soil with 25 $\mathrm{mL}$ of distilled water which was magnetically agitated for 20 min. After sedimentation, the aqueous supernatant phase was prepared to analysis. All the samples (pre and post mortem) were filtered with $0.45 \mu \mathrm{m}$ nylon filters from Whatman before their analysis. The atrazine and oxyfluorfen concentration in the liquid samples daily was determined 
1 acetate/hexane $(2 \% \mathrm{v} / \mathrm{v})$ solution for the extraction of atrazine, while for the oxyfluorfen

2 extraction, the sample was mixed with $5 \mathrm{~mL}$ of ethyl acetate. In every extraction step, the

3 soil was mixed with the corresponding volume of solvent and agitated vigorously in a

4 vortex agitator for $5 \mathrm{~min}$. Samples were taken from the organic supernatant phase were

5 analyzed.

6 The decay of herbicides was followed by reversed-phase chromatography and total

7 organic carbon (TOC). The chromatography system was anAgilent 1100 series coupled a

8 UV detector. The analytical column Phenomenex Gemini $5 \mu \mathrm{m} \mathrm{C} 18$ was used. For the

9 four compounds, the temperature oven was maintained at $25{ }^{\circ} \mathrm{C}$ and volume injection of $20 \mu \mathrm{L}$. 2,4 D was identified using mobile phase consisted of $60 \%$ acetonitrile and $40 \%$ water to $2 \%$ acetic acid with a flow rate of $0.4 \mathrm{~mL} \mathrm{~min}^{-1}$ and detection wavelength of 280 nm. The mobile phase for Chlorsulfuron analysis consisted of $40 \%$ acetonitrile and $60 \%$ water $\left(0.1 \% \mathrm{H}_{3} \mathrm{PO}_{4}\right)$ with a flow rate of $0.4 \mathrm{~mL} \mathrm{~min}^{-1}$. The detection wavelength used was $225 \mathrm{~nm}$. The atrazine concentration was measured using a mixture of acetonitrile/water (45:55 v/v) at $0.3 \mathrm{~mL} \mathrm{~min}^{-1}$ as mobile phase and at $223 \mathrm{~nm}$. Oxyfluorfen was quantified using mobile phase acetonitrile/water $(70: 30 \mathrm{v} / \mathrm{v})$ at $0.25 \mathrm{~mL} \mathrm{~min}^{-1}$ and detection wavelength of $220 \mathrm{~nm}$.

Total Organic Carbon (TOC) concentration was monitored using a Multi N/C 3100 Analytik Jena analyzer. Measurements of $\mathrm{pH}$ were carried out with an InoLab WTW pHmeter. Conductivity was measured using a Conductimeter GLP 31 (Crisol Instruments, Spain). The soil temperature was monitored using a Digital Soil thermometer.

\section{Results and discussion}


1 Figure 1 shows the changes in the current density during the $15 \mathrm{~d}$ tests in which the

2 electrokinetic soil flushing of synthetic polluted soils with the four herbicides are 3 evaluated.

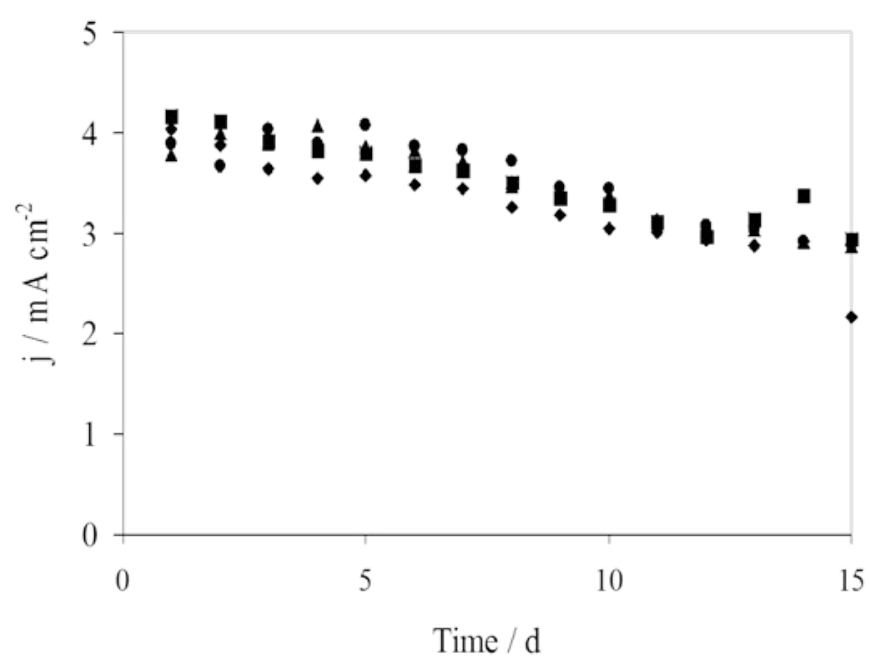

6

7 Figure 1. Changes in the current density, as a function of treatment time, during the 8 remediation of the soil by electroremediation at $1.0 \mathrm{~V} \mathrm{~cm}^{-1}$. Pesticides: 2,4-D ( $\left.\mathbf{\square}\right)$; 9 chlorsulfuron $(\diamond)$; oxyfluorfen $(\boldsymbol{\Delta})$ and atrazine $(\boldsymbol{O})$.

11 As it can be observed, current density is not negligible but important and the values are 12 similar in the four tests performed. A decrease is achieved as a function of time, from an 13 initial value of nearly $4.0 \mathrm{~mA} \mathrm{~cm}^{-2}$ at a rate of $0.1 \mathrm{~mA} \mathrm{~cm}^{-2} \mathrm{~d}^{-1}$ to $2.9 \mathrm{~mA} \mathrm{~cm}^{-2}$. As it is 14 known, current density can be understood as a globalized measurement of the rate of the 15 electrochemical processes (both electrodic and electrokinetic) and accounts for several 16 factors being the most significant the conductivity of soil and the reactions taking place 17 on the anode and cathode surfaces. Considering the type of electrodes used, only water 
1 oxidation and reduction (Eq. 1 and 2) can be expected because graphite anodes are burned

2 at a lower overpotential than that required for the herbicides oxidation.

$$
\begin{aligned}
& \mathrm{H}_{2} \mathrm{O}-2 \mathrm{e}^{-} \longrightarrow 1 / 2 \mathrm{O}_{2}+2 \mathrm{H}^{+} \\
& \mathrm{H}_{2} \mathrm{O}+\mathrm{e}^{-} \longrightarrow 1 / 2 \mathrm{H}_{2}+\mathrm{OH}^{-}
\end{aligned}
$$

These two electrochemical reactions are confirmed with the changes in the $\mathrm{pH}$ of the anode and cathode compartments during the electrokinetic tests. As it can be observed in the SM (Fig. SM-2), the $\mathrm{pH}$ in the anode compartments decreases down to 2 while the $\mathrm{pH}$ in the cathode compartments increases up to almost 14, confirming the progress of equations 1 and 2.

Only small differences are observed between the four different soil remediation tests and in less than $6 \mathrm{~d}$ of treatment, the $\mathrm{pH}$ seems to have almost reached the steady state value. These changes in the $\mathrm{pH}$ of the electrolyte wells must reflect on the profile of $\mathrm{pH}$ in the soil due to the diffusion and migration of the ions. Meanwhile, Fig. 2 shows the changes of $\mathrm{pH}$ after the $15 \mathrm{~d}$ treatment in the soil, measured after the postmortem analysis. As expected, a profile of $\mathrm{pH}$ is obtained in the soil showing clearly the acidic and alkaline fronts, which are neutralized at the central positions of the soil. In this point, it is important to bear in mind that the acidic and alkaline front may have significant effects on the precipitation and ion exchange properties of the soil. Despite following the same trend along the soil, $\mathrm{pH}$ in the upper sections are slightly alkaline than in the bottom section. This trend, although repetitive in the four tests carried out, is difficult to explain unless it is taking into account that the electroosmotic flux that flows preferentially in the upper position because the anode and cathode plates are connected in the upper part leading to a non-uniform current distribution, for which the maximum current is near to the connection. 

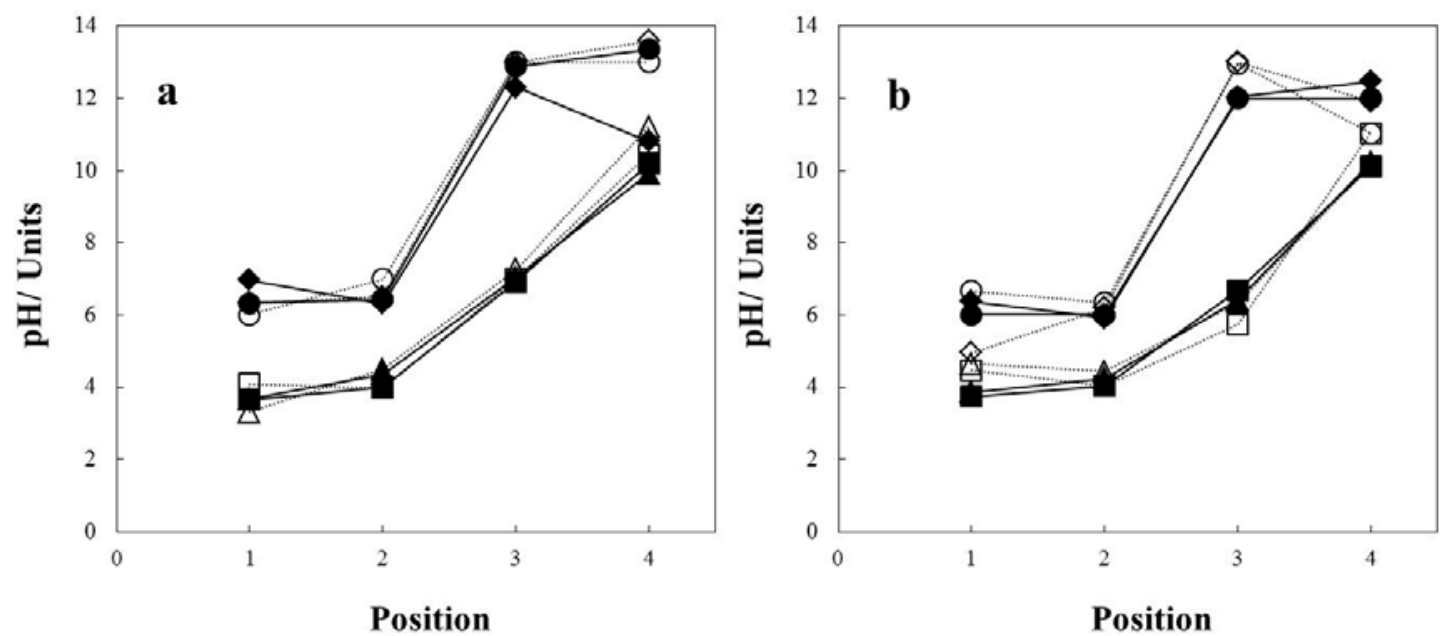

Figure 2. (a) pH map of the soil after the remediation test for a) 2,4 D (full symbols) and chlorsulfuron (empty symbols), b) Atrazine (full symbols) and oxyfluorfen (empty symbols) remediation. Upper right position $(\bullet, \circ)$, upper left position $(\mathbf{\bullet}, \square)$, bottom right position $(\diamond, \diamond)$ and bottom left position $(\boldsymbol{\Delta}, \Delta)$ of the soil after the remediation test. Note that the positions are based on the Fig. SM-1b.

Figure 3 shows the changes in the conductivity of the electrolyte wells during the electroremediation tests. As expected, concentration of ions increases significantly in the anolyte and catholyte compartments during the complete test. These increasing concentrations of ions are derived from the accumulation of protons and hydroxyl ions in the anode and cathode compartments, respectively. Despite the $\mathrm{pH}$ seems to be stabilized, conductivity continuous increasing. This different trend (from that of the $\mathrm{pH}$ changes) indicates that conductivity does not only consider the concentration of hydroxyl and proton ions but it also considers other ions transported from the soil to the wells. Moreover, this can be also well explained with the accumulation of water-electrolysis products because of the logarithmic scale of $\mathrm{pH}$. Anyhow, after $9 \mathrm{~d}$ of operation, the conductivity changing rate seems to decrease and to stabilize in a value, considerably 
1 higher in the case of oxyfluorfen than in the case of the other pesticides, in particular in

2 the anode compartment. These differences may be related to the ionic character of each

3 pesticide or to the charge of the colloid surfactant/herbicide. In fact, the pKa constants

4 for the different pesticides are 1.60, 2.76 and 3.60 for atrazine, 2,4-D and chlorsulfuron

5 (Table SM-1), respectively (oxyfluorfen has no ionizable groups), meaning that 2,4-D

6 and chlorsulfuron are fully ionizated at the $\mathrm{pH}$ conditions of the soil while atrazine and

7 oxyfluorfen remains as non-charge species and hence its mobility inside an electric field 8 depends on the ionization of the surfactant species.

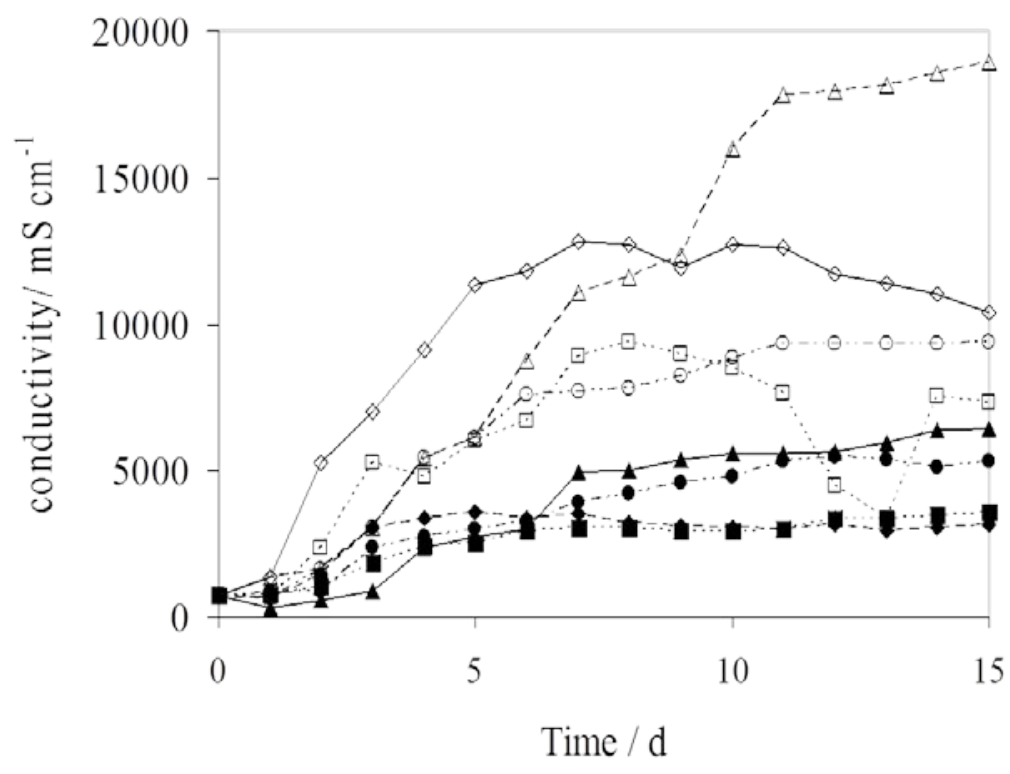

10

11 Figure 3. Changes in the conductivity of the electrolyte wells at cathodic and anodic compartments, as a function of time: 2,4-D $(\boldsymbol{\square}, \square)$; chlorsulfuron $(\diamond, \diamond)$; oxyfluorfen $(\boldsymbol{\Lambda}, \triangle)$; atrazine $(\boldsymbol{\bullet}, \bigcirc)$. Full symbol: cathode; Empty symbol: anode.

The transport of ions from the soil to the electrolyte is well-confirmed in the postmortem analysis (Fig. SM-3 of SM), where it can be observed that the initial value of conductivity decreases from the initial $387 \mathrm{mS} \mathrm{cm}^{-1}$ down to less than $200 \mathrm{mS} \mathrm{cm}^{-1}$. The high values 
1 obtained in some points may be related to specific zones where particular heterogeneity

2 of the soil matrix was achieved, favoring the eventual accumulation of ions in these

3 regions.

4

On the other hand, it is expected the transport of water from the anode to the cathode 5 wells by the well-known electro-osmosis because of the application of an electric field. 6 Figure 4 shows changes in the electro-osmotic fluxes produced in the soils during the four 7 tests. Initially, the soil shows a tendency to retain water and, consequently, in this first stage water did not accumulate in the cathodic wells and the electroosmosis flux was null. After this initial period, water is continuously accumulated in the cathodic well and it is 10 directly related to the electroosmotic flux. Not very important differences can be noticed in the four tests carried out, and in all cases, electroosmotic flows trend to stabilize around $1 \mathrm{~mL} \mathrm{~cm}^{-2} \mathrm{~d}^{-1}$ after $10 \mathrm{~d}$ of treatment. The differences observed may be related to the initial moisture of the soil and to the extension of other non-electrokinetic processes such 14 as evaporation, as we will discuss later.

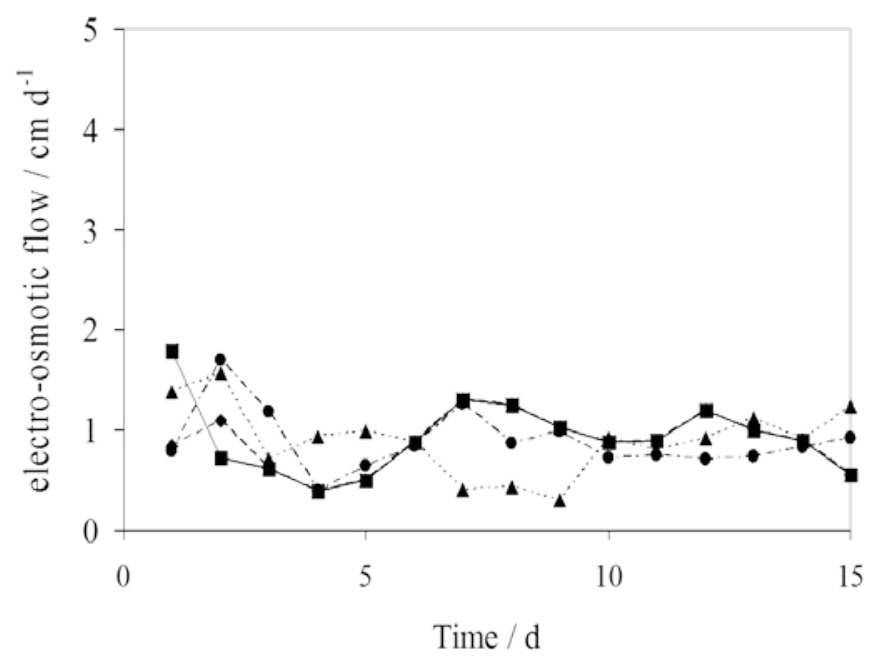

17 Figure 4. Changes in the electro-osmotic fluxes produced in the soils during the electrokinetic tests. 2,4-D ( $\mathbf{\square})$; chlorsulfuron $(\bullet)$; oxyfluorfen $(\boldsymbol{\Delta})$ and atrazine 
The continuous addition and extraction of water during the electroremediation process 3 can produce significant changes in the moisture of the soil. Figure SM-4 in the SM shows

4 5

the moisture of the soil after the $15 \mathrm{~d}$ treatment. Axial dispersion points out the complexity of the transport of water with fluctuations over $5 \%$ in each one of the positions. As it can be observed, moisture does not change abruptly and it maintains around the initial value (30\%), being slightly lower in the case of atrazine. In general, it was observed that the water distribution is quite uniform and the slight differences can be related to specific zones where particular heterogeneity was achieved and preferential pathways formed in the soil during the compaction stage. The lower final moisture attained during the atrazine test may be related to the lower initial value attained in this case and not to electroremediation process.

Besides $\mathrm{pH}$ and conductivity, the most important parameter in the study is the concentration of pesticide remaining in the soil after the treatment. Figure 5 shows the concentration map of pesticides in the four tests. As it can be observed, except in the case of chlorsulfuron, after $15 \mathrm{~d}$ of treatment, the concentration of pesticides remained in the soil has decreased until values lower than $10 \mathrm{mg}$ per kg of soil, and even markedly lower in the case of 2,4-D (below $3.8 \mathrm{mg}$ of 2,4-D per kg of soil). For a better comparison, the average pollutant concentration in the soil is shown in the SM (Fig. SM-5). As it can be observed, after $15 \mathrm{~d}$ of treatment, 2,4-D is the pesticide most efficiently removed, whereas the results obtained with chlorsulfuron are surprisingly worse. The significantly high values of chlorsulfuron in the central region of the soil after the treatment (even higher than the average initial value of $30 \mathrm{mg}$ per $\mathrm{kg}$ of soil), and the low values of chlorsulfuron in the regions close to electrolyte wells (even nil in the cathodic well, position 4) can be related to a non-homogeneous distribution in the soil of the pesticide. Likewise, the 
1 existence of specific zones with particular heterogeneity of the soil matrix and the

2 subsequent accumulation of pollutants in non-controlled points can also help to explain

3 the outsider points. On the other hand, the final distribution of the two non-polar

4 pesticides is quite homogeneous and the removal percentage attained after the $15 \mathrm{~d}$ test is

5 similar in both cases with final concentrations around $5 \mathrm{mg} \mathrm{kg}^{-1}$ of soil, achieving around

$680 \%$ of removal during the treatment of soil polluted with non-polar pesticides (atrazine

7 and oxyfluorfen) and more than 96\% in the case of 2,4-D polluted soil.

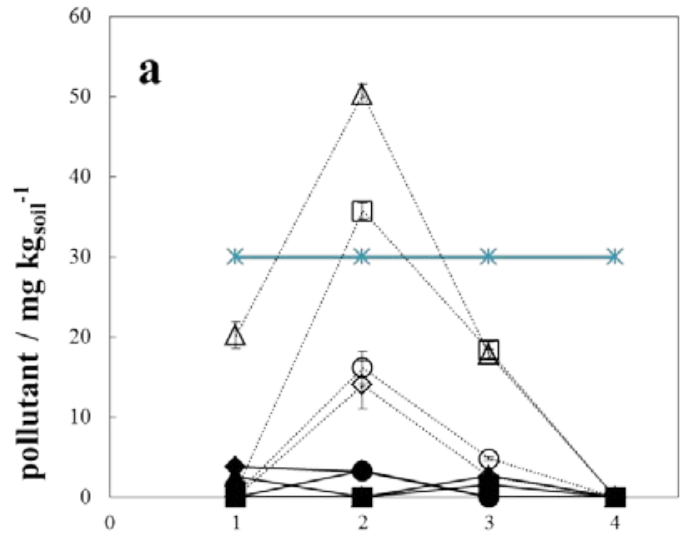

Position

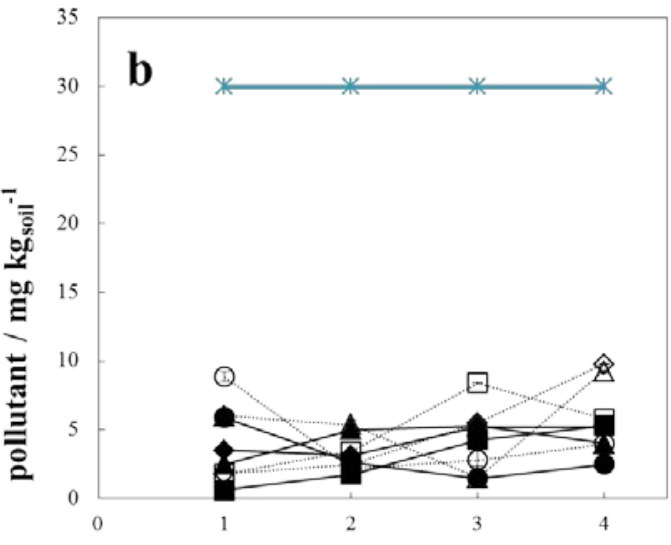

Position

Figure 5. Concentration map of the soil after the remediation test (a) 2,4 D (full symbols) and chlorsulfuron (empty symbols), (b) atrazine (full symbols) and oxyfluorfen (empty symbols). Upper right position (•, o), upper left position $(\boldsymbol{\bullet}, \square)$, bottom right position ( $\diamond)$ and bottom left position $(\boldsymbol{\Lambda}, \Delta)$ of the soil after the remediation test. $\left(^{*}\right)$ initial concentration. Note that the positions are based on the Fig. SM1-b.

To determine the main mechanisms of transport involved in the electroremediation process, the concentration of pesticide in anodic and cathodic wells was monitored during the treatment, and the amount of pesticide evaporated was estimated by mass balance. Figure 6 summarizes the amount of the four pesticides collected at anodic and cathodic 
1

wells, the amount transferred to the atmosphere and the amount remaining in the soil after each electroremediation test. In this point, it is important to point out that in all tests, water was used as flushing fluid and thus, it can be expected that the polar character of 2,4-D and chlorsulfuron favors the drainage of them with the electro-osmotic flux. However, the negative charge of 2,4-D molecules also favors its transport to the anode wells by electromigration. In fact, the amount of 2,4-D collected in the anode/s is more important than that collected in the cathode/s, indicating that for this application, electromigration is more significantly important than drainage by electro-osmotic flux. Similar results were obtained in the case of chlorsulfuron. These figures are in agreement with the pKa values for each one of the pesticides and their ionizability (see Fig. 3).

In the case of non-polar pesticide, it is important to take in mind that a solubilizing agent was used and colloids formed behaves as charge particles that can be moved in the soil by means of the electric field (due to the anionic character of the surfactant used it is attracted to the positively charged electrode) or these can be drained with electroosmotic flux towards cathodic wells. On basis of the results obtained, these compounds are majority transport by means of electromigration flux, although the amount of non-polar pesticide collected at cathode is higher than those observed in the case of polar pesticides. Besides this observation, in all cases, it must be pointed out the important contribution of non electrokinetic processes, with percentage of removal by evaporation around $60 \%$. Recent studies (Risco et al., 2015, 2016) have shown that these losses may be mainly linked to the air transfer during the pollution process, while the humidification attained in the electrokinetic treatment minimizes the amount that is transferred to the air, which would be an important aspect of the treatment (Trellu et al., 2016). This loss is a significant risk that should be assessed in the event of an actual treatment site and thus, the use of capillary barriers on the surface of the soil and of gas-extraction system in 
1 electrolyte wells can help to prevent the loses of pesticides to atmosphere. Side processes,

2 such as the electrochemical oxidation of pesticides, are not expected because of the

3 electrodes used. Previous experiments point out that no electrolysis or adsorption is

4 produced in the conditions tested. Likewise, the use of synthetic soil prevents other

5 potential side processes like adsorption (soil shows no capacity to retain the pesticides)

6 or biological oxidation (soil contains no significant concentration of microorganisms and 7 lacks nutrients).

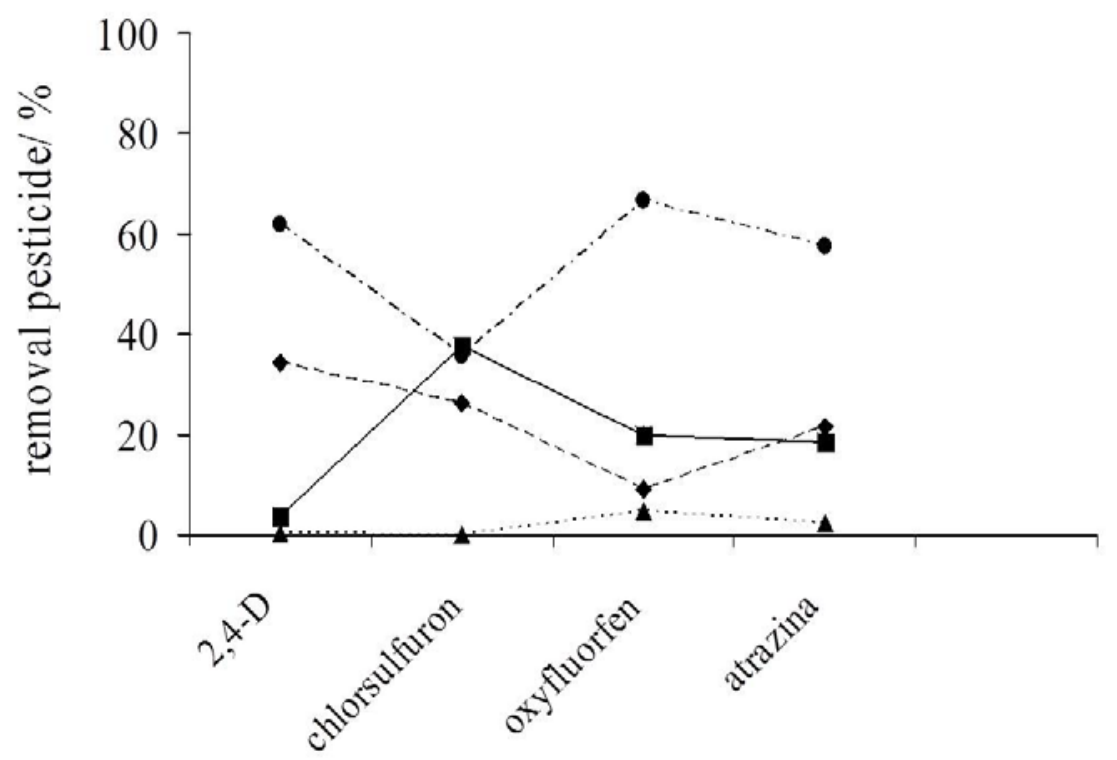

Figure 6. Significance of the transport mechanisms in the removal of the pesticides tested.

11 Remaining in soil after the treatment $(\mathbf{\square})$; collected at anode $(\bullet)$; collected at cathode

Finally, in the SM is shown the average water and pesticide evaporation rate estimated during the four tests carried out (Fig. SM-6). As it can be observed, except in the case of 16 chlorsulfuron test that shows a lower air transfer rate, the water and pesticide evaporation 
1

10

11

12

rates are around $0.25 \mathrm{~mL} \mathrm{~cm}^{-2} \mathrm{~d}^{-1}$ and $0.02 \mathrm{mg} \mathrm{mL}^{-1} \mathrm{~d}^{-1}$, respectively. To confirm the importance of air transfer processes in this type of treatment, water and pesticide evaporation were measured in separated tests and it was found at room temperature (around $20-25^{\circ} \mathrm{C}$ ) the average water evaporation rate is around $0.24 \mathrm{~mL} \mathrm{~cm}^{-2} \mathrm{~d}^{-1}$, which are consistent with the water evaporation rate estimated from experimental data. Respect to air transfer of pesticide; it depends on the pressure vapor of each one of the pesticides. According to data given in the Table SM-1, chlorsulfuron presents a significantly lower volatility than that the others pesticides tested and this can help to explain the lower chlorsulfuron evaporation rate and even the lower removal percentage attained during this electroremediation test.

\section{Conclusions}

The following conclusions can be observed as a result of this study:

- The decontamination of soils by EKSF is a feasible process for the remediation of soils polluted with polar and non-polar pesticides. Nevertheless, the transport of the non-polar pesticides is strongly promoted with the addition of surfactants to non-polar pollutant.

- Non relevant differences are observed in terms of $\mathrm{pH}$ and conductivity. The outsider values obtained in some cases may be related to specific zones where particular heterogeneity of the soil matrix was achieved, favoring the eventual accumulation of ions in these regions.

- Electroosmotic flux does not depend significantly on the nature of the pesticide, in all cases; it stabilizes around $1 \mathrm{~mL} \mathrm{~cm}{ }^{-2} \mathrm{~d}^{-1}$ after $10 \mathrm{~d}$ of treatment.

- In an electrokinetic remediation process, pesticides are mobilized towards the anode primarily by electromigration; although it depends on the properties of the pesticides (i.e. 
1 ionizability, pKa). However, significant concentrations of pesticides are detected at

2 cathode due to the action of electroosmotic drag.

3 - The EKSF technology can eliminate more than $80 \%$ of the pollution by electrokinetic

\section{Acknowledgements} Brazil).

\section{References} 87-93. and evaporation fluxes over a $15 \mathrm{~d}$ test, although a significant percentage is related to air transfer process. Side processes, such as the electrochemical oxidation of pesticides, are not expected because of the electrodes used. Likewise, the use of synthetic soil prevents other potential side processes like adsorption or biological oxidation.

The authors acknowledge funding support from the EU and Spanish Government through the MINECO Project CTM2013-45612-R, FEDER 2007-2013 PP201010 (Planta Piloto de Estación de Estación de Regeneración de Aguas Depuradas) and INNOCAMPUS. C. A. Martínez-Huitle thanks funding from the National Council for Scientific and Technological Development (CNPq - 446846/2014-7 and CNPq- 401519/2014-7,

Alcantara, M., Gomez, J., Pazos, M., Sanroman, M., 2010. Electrokinetic remediation of PAH mixtures from kaolin. J. Hazard. Mat. 179, 1156-1160.

Alcantara, M., Gomez, J., Pazos, M., Sanroman, M., 2012. Electrokinetic remediation of lead and phenanthrene polluted soils. Geoderma 173, 128-133.

Bocos, E., Fernandez-Costas, C., Pazos, M., Sanroman, M., 2015. Removal of PAHs and pesticides from polluted soils by enhanced electrokinetic-Fenton treatment. Chemosphere 125, 168-174. Cao, X., Song, H.L., Yu, C.Y., Li, X.N., 2015. Simultaneous degradation of toxic refractory organic pesticide and bioelectricity generation using a soil microbial fuel cell. Bioresour. Technol. 189,

Castelo-Grande, T., Augusto, P.A., Barbosa, D., 2005. Removal of pesticides from soil by supercritical extraction - A preliminary study. Chem. Eng. J. 111, 167-171.

Dombek, T., Davis, D., Stine, J., Klarup, D., 2004. Degradation of terbutylazine (2-chloro-4ethylamino-6-terbutylamino-1,3,5- triazine), deisopropyl atrazine (2-amino-4-chloro-6ethylamino-1,3,5-triazine), and chlorinated dimethoxy triazine (2-chloro-4,6-dimethoxy-1,3,5triazine) by zero valent iron and electrochemical reduction. Environ. Pollut. 129, 267-275. 
Gomes, H.I., Dias-Ferreira, C., Ribeiro, A.B., 2012. Electrokinetic remediation of organochlorines in soil: Enhancement techniques and integration with other remediation technologies. Chemosphere 87, 1077-1090.

Gomez, J., Alcantara, M., Pazos, M., Sanroman, M., 2009. A two-stage process using electrokinetic remediation and electrochemical degradation for treating benzo[a]pyrene spiked kaolin. Chemosphere 74, 1516-1521.

Guedes, P., Mateus, E., Couto, N., Rodriguez, Y., Ribeiro, A., 2014. Electrokinetic remediation of six emerging organic contaminants from soil. Chemosphere 117, 124-131.

Hamdan, S.H., Molelekwa, G.F., Van der Bruggen, B., 2014. Electrokinetic remediation technique: an integrated approach to finding new strategies for restoration of saline soil and to control seawater intrusion. ChemElectroChem 1, 1104-1117.

Harbottle, M.J., Lear, G., Sills, G.C., Thompson, I.P., 2009. Enhanced biodegradation of pentachlorophenol in unsaturated soil using reversed field electrokinetics. J. Environ. Manage. 90, 1893-1900.

Jackman, S.A., Maini, G., Sharman, A.K., Sunderland, G., Knowles, C.J., 2001. Electrokinetic movement and biodegradation of 2,4-dichlorephenoxyacetic acid in silt soil. Biotechnol. Bioeng. $74,40-48$.

Lopez-Vizcaino, R., Alonso, J., Canizares, P., Leon, M., Navarro, V., Rodrigo, M., Saez, C., 2014a. Electroremediation of a natural soil polluted with phenanthrene in a pilot plant. J. Hazard. Mat. 265, 142-150.

Lopez-Vizcaino, R., Alonso, J., Canizares, P., Leon, M., Navarro, V., Rodrigo, M., Saez, C., 2014b. Removal of phenanthrene from synthetic kaolin soils by electrokinetic soil flushing. Sep. Purif. Technol. 132, 33-40.

Malpass, G.R.P., Miwa, D.W., Machado, S.A.S., Olivi, P., Motheo, A.J., 2006. Oxidation of the pesticide atrazine at DSA ${ }^{\circledR}$ electrodes. J. Hazard. Mat. 137, 565-572.

Martínez-Huitle, C.A., Rodrigo, M.A., Sirés, I., Scialdone, O., 2015. Single and coupled electrochemical processes and reactors for the abatement of organic water pollutants: a critical review. Chem. Rev. 115, 13362-13407.

Maturi, K., Reddy, K., 2006. Simultaneous removal of organic compounds and heavy metals from soils by electrokinetic remediation with a modified cyclodextrin. Chemosphere 63, 1022-1031.

Maturi, K., Reddy, K., 2008. Cosolvent-enhanced desorption and transport of heavy metals and organic contaminants in soils during electrokinetic remediation. Water Air Soil Pollut. 189, 199211.

Mendez, E., Perez, M., Romero, O., Beltran, E., Castro, S., Corona, J., Corona, A., Cuevas, M., Bustos, E., 2012. Effects of electrode material on the efficiency of hydrocarbon removal by an electrokinetic remediation process. Electrochim. Acta 86, 148-156.

Mousset, E., Oturan, N., van Hullebusch, E.D., Guibaud, G., Esposito, G., Oturan, M.A., 2014. Treatment of synthetic soil washing solutions containing phenanthrene and cyclodextrin by electro-oxidation. Influence of anode materials on toxicity removal and biodegradability enhancement. Appl. Catal. B: Environ. 160-161, 666-675.

Ribeiro, A., Mateus, E., Rodriguez-Maroto, J., 2011. Removal of organic contaminants from soils by an electrokinetic process: The case of molinate and bentazone. Experimental and modeling. Sep. Purif. Technol. 79, 193-203.

Ribeiro, A., Rodriguez-Maroto, J., Mateus, E., Gomes, H., 2005. Removal of organic contaminants from soils by an electrokinetic process: the case of atrazine. Experimental and modeling. Chemosphere 59, 1229-1239.

Risco, C., López-Vizcaíno, R., Sáez, C., Yustres, A., Cañizares, P., Navarro, V., Rodrigo, M.A., 2016. Remediation of soils polluted with 2,4-D by electrokinetic soil flushing with facing rows of electrodes: A case study in a pilot plant. Chem. Eng. J. 285, 128-136.

Risco, C., Rodrigo, S., López-Vizcaíno, R., Yustres, A., Sáez, C., Cañizares, P., Navarro, V., Rodrigo, M.A., 2015. Electrochemically assisted fences for the electroremediation of soils polluted with 2,4-D: A case study in a pilot plant. Sep. Purif. Technol. 156, Part 2, 234-241. 
1 Rodrigo, M., Oturan, N., Oturan, M., 2014. Electrochemically assisted remediation of pesticides 2 in soils and water: A Review. Chem. Rev. 114, 8720-8745.

3 Trellu, C., Mousset, E., Pechaud, Y., Huguenot, D., van Hullebusch, E.D., Esposito, G., Oturan, 4 M.A., 2016. Removal of hydrophobic organic pollutants from soil washing/flushing solutions: A 5 critical review. J. Hazard. Mat. 306, 149-174.

6 